\title{
Quantitative Trait Locus Mapping of Human Blood Pressure to a Genetic Region at or near the Lipoprotein Lipase Gene Locus on Chromosome 8p22
}

\author{
Du-An Wu, ${ }^{\star}$ Xiangdong Bu, ${ }^{\ddagger}$ Craig H. Warden, ${ }^{*}$ David D.C. Shen,, C.-Y. Jeng,, Wayne H.H. Sheu, Martin M.T. Fuh, \\ Tomohiro Katsuya, ${ }^{\S}$ Victor J. Dzau, ${ }^{\S}$ Gerald M. Reaven, ${ }^{\S}$ Aldons J. Lusis, ${ }^{\star}$ Jerome I. Rotter, ${ }^{\ddagger}$ and Y.-D. Ida Chen ${ }^{\S}$ \\ *Department of Medicine, Department of Microbiology and Molecular Genetics, and Molecular Biology Institute, UCLA, Los Angeles, \\ California 90024; ${ }^{\ddagger}$ Departments of Medicine and Pediatrics, Cedars-Sinai Research Institute and UCLA, Los Angeles, California 90048; \\ ${ }^{\S}$ Department of Medicine, Stanford University, Stanford, California 94305; and ${ }^{\prime}$ Department of Medicine, Triservice General Hospital, \\ Taipei, Taiwan
}

\begin{abstract}
Resistance to insulin-mediated glucose disposal is a common finding in patients with non-insulin-dependent diabetes mellitus (NIDDM), as well as in nondiabetic individuals with hypertension. In an effort to identify the generic loci responsible for variations in blood pressure in individuals at increased risk of insulin resistance, we studied the distribution of blood pressure in 48 Taiwanese families with NIDDM and conducted quantitative sib-pair linkage analysis with candidate loci for insulin resistance, lipid metabolism, and blood pressure control. We found no evidence for linkage of the angiotensin converting enzyme locus on chromosome 17 , nor the angiotensinogen and renin loci on chromosome 1 , with either systolic or diastolic blood pressures. In contrast, we obtained significant evidence for linkage of systolic blood pressure, but not diastolic blood pressure, to a genetic region at or near the lipoprotein lipase (LPL) locus on the short arm of chromosome $8(P=0.002, n=125$ sib-pairs, for the haplotype generated from two simple sequence repeat markers within the LPL gene). Further strengthening this linkage observation, two flanking marker loci for LPL locus, D8S261 (9 cM telomeric to LPL locus) and D8S282 (3 cM centromeric to LPL locus), also showed evidence for linkage with systolic blood pressure $(P=0.02$ and 0.0002 for D8S261 and D8S282, respectively). Two additional centromeric markers (D8S133, $5 \mathrm{cM}$ from LPL locus, and NEFL, $11 \mathrm{cM}$ from LPL locus) yielded significant $P$ values of 0.01 and 0.001 , respectively. Allelic variation around the LPL gene locus accounted for as much as $52-73 \%$ of the total interindividual variation in systolic blood pressure levels in this data set. Thus, we have identified a genetic locus at or near the LPL gene locus which contributes to the variation of systolic blood pressure levels in nondiabetic family members at high risk for insulin resistance and NIDDM. ( $J$.
\end{abstract}

Address correspondence to Jerome I. Rotter, M.D., Division of Medical Genetics, SSB-3, Cedars-Sinai Medical Center, 8700 Beverly Blvd., Los Angeles, CA 90048. Phone: 310-855-6467; FAX: 310-6590491.

Received for publication 21 February 1995 and accepted in revised form 20 February 1996.

J. Clin. Invest.

(C) The American Society for Clinical Investigation, Inc.

0021-9738/96/05/2111/08 \$2.00

Volume 97, Number 9, May 1996, 2111-2118
Clin. Invest. 1996. 97:2111-2118.) Key words: sib-pair • candidate gene $\bullet$ insulin resistance $\bullet$ diabetes $\bullet$ flanking marker

\section{Introduction}

Resistance to insulin-mediated glucose disposal is a characteristic feature of individuals with non-insulin-dependent diabetes mellitus (NIDDM) ${ }^{1}$ and has been shown to be present before the development of hyperglycemia (1-3). It has also been suggested that resistance to insulin-mediated glucose disposal and/or compensatory hyperinsulinemia increase the likelihood that nondiabetic individuals will develop a cluster of abnormalities, including mild glucose intolerance, high plasma triglyceride and low high density lipoprotein-cholesterol concentration, and high blood pressure (4). In addition, family studies having shown that nondiabetic individuals with relatives having NIDDM share many of these features as well, suggesting an appreciable genetic component to the familial aggregation of the metabolic abnormalities associated with insulin resistance (5-9).

Patients with NIDDM are not only insulin resistant, but also have an increased prevalence of hypertension (10). In addition, insulin resistance is a common finding in patients with high blood pressure $(4,11)$. We have attempted to take advantage of the relationships between insulin resistance, NIDDM, and hypertension in a study aimed at examining the genetic mechanisms contributing to regulation of blood pressure. Specifically, we studied the variation in blood pressure and the segregation of molecular genetic markers at candidate gene loci in 48 Taiwanese families with at least one parent affected with NIDDM. Nonparametric sib-pair linkage methodology, which compares the quantitative variation of a trait with the number of marker alleles shared identical-by-descent, was used since it makes no assumptions regarding the mode of inheritance (12-14). To avoid analytic complications resulting from metabolic consequences of diabetes, only the blood pressures in the nondiabetic offspring in these families were used in the genetic statistical analysis. The results reveal evidence for linkage between systolic blood pressure, and not diastolic, and markers at the lipoprotein lipase (LPL) locus on chromosome $8 \mathrm{p} 22$.

\footnotetext{
1. Abbreviations used in this paper: $\mathrm{ACE}$, angiotensin-converting enzyme; BMI, body mass index; LPL, lipoprotein lipase; NEFL, neurofilament light polypeptide; NIDDM, non-insulin-dependent diabetes mellitus; SSRP, simple sequence repeat polymorphism.
} 
Table I. Candidate Gene Loci Examined in Taiwan NIDDM Families

\begin{tabular}{|c|c|c|c|}
\hline Physiology & Locus & $\begin{array}{c}\text { Chromosomal } \\
\text { location }\end{array}$ & References \\
\hline \multirow[t]{5}{*}{ Glucose-related loci } & Glucokinase 1 and 2 & $7 \mathrm{p} 11.2$ & 18 \\
\hline & Adenosine deaminase gene & 20q13.11 & 19 \\
\hline & Glucagon receptor: D17S784 & $17 \mathrm{q} 25$ & 20 \\
\hline & Rh linked SSRP (D1S199, D1S234) & $1 \mathrm{p}$ & 20 \\
\hline & Rh linked SSRP (c- $f g r$ protooncogene, FGR) & $1 \mathrm{p}$ & 21 \\
\hline \multirow[t]{2}{*}{ Insulin-related loci } & IRS-1 & $2 q 36$ & 22 \\
\hline & D11S928 (familial hyperinsulinemia) & $11 \mathrm{p}$ & 20,23 \\
\hline \multirow[t]{10}{*}{ Lipid metabolism } & Apolipoprotein A1-C3-A4: apo C3 & $11 \mathrm{q} 23-24$ & 24,25 \\
\hline & Apolipoprotein C1-C2-E & $19 \mathrm{q} 13.2$ & 26 \\
\hline & CETP linked SSRP (D16S313) & $16 \mathrm{q} 21$ & 27 \\
\hline & CETP linked SSRP (D16S397, D16S490) & $16 \mathrm{q} 21$ & Personal communication \\
\hline & CETP linked SSRP (D16S503, D16S512) & $16 \mathrm{q} 21$ & 20 \\
\hline & $\operatorname{LPL}\left(5^{\prime}\right.$ and $3^{\prime}$ SSRP $)$ & $8 \mathrm{p} 22$ & 28 \\
\hline & LPL linked SSRP (D8S261) & $8 \mathrm{p} 22$ & 29 \\
\hline & LPL linked SSRP (D8S266, D8S282) & $8 \mathrm{p} 22$ & 20 \\
\hline & LPL linked SSRP (NEFL) & $8 \mathrm{p} 22$ & 30 \\
\hline & LPL linked SSRP (D8S133) & $8 \mathrm{p} 22$ & 31 \\
\hline \multirow[t]{6}{*}{ Blood pressure } & ACE: ACE I/D & $17 \mathrm{q} 23$ & 33 \\
\hline & ACE linked SSRP (growth hormone) & $17 \mathrm{q} 23$ & 33 \\
\hline & ACE linked SSRP (D17S787) & $17 \mathrm{q} 23$ & 20 \\
\hline & Renin & $1 q$ & 34 \\
\hline & Angiotensinogen: RFLP & $1 q 42-43$ & 35 \\
\hline & Angiotensinogen: SSRP & $1 q 42-43$ & 36 \\
\hline
\end{tabular}

Personal communication from Research Genetics (Huntsville, AL).

\section{Methods}

Family ascertainment. 48 Chinese nuclear families were ascertained through a proband with documented NIDDM at the Diabetes Clinics of Triservice General Hospital, Taipei, Taiwan. In 31 families, both parents had documented NIDDM, whereas in 17 families only one parent was affected. A total of 222 individuals and 96 parents from these 48 families was included in the study, including 126 nondiabetic offspring defined by the oral glucose tolerance test criteria (15). The investigation was approved by the institutional Human Subjects Protection Committee (Triservice General Hospital, Taiwan).

Phenotypic traits. Age, sex, onset age of NIDDM, weight, and height were obtained in each participating individual. Levels of systolic and diastolic pressure were measured in the sitting position three times at 20-min intervals by an experienced nurse, and the mean value was taken for systolic or diastolic pressure, respectively. The sphygmomanometer had a cuff width of $14.5 \mathrm{~cm}$ (Nitirin, Nippon Rinsho Kikai, Kogyo Co. Ltd., Tokyo, Japan). For each participating offspring, a total of $20 \mathrm{ml}$ of blood was obtained at $0,30,60,90$, and $120 \mathrm{~min}$ in an oral glucose tolerance test ( 75 grams of glucose). Plasma glucose and insulin levels were measured by enzymatic colorimetric method (16) and by radioimmunoassay (17), respectively. Surveillance samples measured quarterly using these protocols met the criteria of standardization required by the Centers for Disease Control (Atlanta, GA).

Genotyping. DNA was extracted from peripheral white cells. Polymorphic microsatellite markers at or near candidate gene loci were typed (Table I). PCR was performed in a 96-well plate using a programmable thermal cycler (PTC-100; MJ Research, Inc., Watertown, MA) $94^{\circ} \mathrm{C}$ for $1 \mathrm{~min}, 58^{\circ} \mathrm{C}$ for $30 \mathrm{~s}, 72^{\circ} \mathrm{C}$ for $1 \mathrm{~min}$, for a total of 30 cycles. The labeled PCR products were denatured and separated on a $5 \%$ sequencing gel. Autoradiography was performed without an intensifying screen for 5-6 h at room temperature. The genotypes were scored by sizing. The angiotensinogen-converting enzyme (ACE) polymorphism was typed as described (32).

Analytic strategy including statistical linkage analysis. Before formal statistical and linkage analyses, each variable was adjusted for age, sex, and body mass index (BMI) by linear regression analysis using the BMDP computer program package (37). However, to maximize the information for the reader, the distributions of blood pressure and the mean \pm SD are shown as their original raw values. For data quality control, we used the LODLINK subroutine computer program of the Statistical Analysis for Genetic Epidemiology computer program package to check for any genotype inconsistencies (14). For a given region with multiple typed markers, we also used the LODLINK program to calculate the marker-marker linkage distance. No significant deviation from published data was observed.

Linkage analyses were performed on sib-pairs with the SIBPAL computer program of the S.A.G.E. package (14). The underlying basis for the sib-pair linkage approach is to compare the quantitative variation in a trait between siblings as a function of the number of marker alleles they share identical-by-descent. The underlying trait can follow either Mendelian or non-Mendelian modes of inheritance. In this study, linkage was assessed for continuous traits such as systolic blood pressure and diastolic blood pressure against various candidate gene loci. A one-tailed Student's $t$ statistic was used to test the significance of the regression of the squared trait differences versus the number of marker alleles shared identical-by-descent among sibpairs. If any sib-pair square difference was $>3 \mathrm{SD}$ from the mean sibpair squared difference, then the regression was determined after deleting these outlying values.

In our sib-pair linkage analysis, we took several measures to control any possible bias and to avoid false-positive results. Firstly, we have excluded from our analyses those sibs with extreme trait values, i.e., beyond the mean \pm 3 SD. Secondly, we used the more conservative unweighted least-squares option during the sib-pair analysis. 
Thirdly, we have restricted our analysis to only those families with both parental marker genotypes available. This makes the linkage analyses independent of marker allele frequency. This is particularly relevant since the frequency of most of these marker alleles in the Chinese are not as well characterized as in the Caucasian population. Lastly, due to the fact that one or both parents for a given family can be homozygous for the marker typed and, thus an unambiguous identical-by-descent status of sib-pairs could not always be determined, we repeated our analysis a second time using only those families with both parents who were heterozygous for the marker typed. Given adequate sample size, a true linkage result will be robust to all of the above listed maneuvers. Given these maneuvers and the fact that this study used a candidate gene approach, and thus individual hypotheses were being tested, we used $P<0.05$ as our initial criteria for linkage. To further reduce the possibility of a type I error, we genotyped additional flanking markers for any tentative linkage finding.

The contribution of locus variation in the LPL gene to raw adjusted systolic blood pressure levels was estimated by using the sibpair method (12) adopted in Boerwinkle et al. (38) with modification (see Eq. 7 below). More formally, let $Y_{\mathrm{j}}, \pi_{\mathrm{j}}$, and $f_{1 \mathrm{j}}$ be the squared pair differences of a quantitative trait between two siblings, the proportion of genes shared identical-by-descent, and the probability of sharing only one allele for sib pair $\mathrm{j}$, respectively. It has been demonstrated (12) that there is a linear regression of the squared differences $Y_{\mathrm{j}}$ on $\pi_{\mathrm{j}}$ and $f_{1 \mathrm{j}}$, i.e.:

$E\left(Y_{j}\right)=\alpha+\beta \pi_{j}+\gamma f_{l j} ;$

where the coefficients of the regression are:

$\alpha=2 \psi \sigma_{\mathrm{g}}^{2}+\sigma_{\mathrm{e}}^{2}+2 \psi(1-\psi) \sigma_{\mathrm{d}}^{2}$,

$\beta=2(1-2 \psi) \sigma_{\mathrm{g}}^{2}$,

and

$\gamma=(1-\psi) \sigma_{\mathrm{d}}^{2}$.

In the above three equations, $\psi=\theta+(1-\theta)^{2}$, where $\theta$ is the recombination fraction between the trait and marker locus and $\sigma^{2}$ is the variance with subscript $\mathrm{g}$, $\mathrm{d}$, and e standing for the genetic, dominance, and residual components. The heritability (the contribution of the marker loci or nearby genetic region to the variance of the quantitative trait) can be defined as:

$h^{2}=\sigma_{\mathrm{g}}{ }^{2} /\left(\sigma_{\mathrm{g}}^{2}+\sigma_{\mathrm{e}}{ }^{2}\right)$.

It has been shown (13) that when the parental marker data are available and the marker is codominant, the estimated coefficient of the regression of $Y_{\mathrm{j}}$ on $\pi_{\mathrm{j}}$, ignoring $f_{\mathrm{j}}$, is an unbiased estimator of $\beta$, irrespective of what the values of $\sigma_{\mathrm{g}}{ }^{2}$ or $\theta$ may be. Assuming no dominance $\left(\sigma_{\mathrm{d}}^{2}=0\right)$ and no recombination $(\theta=0$, as is the case for the candidate gene approach), Eqs. $1-3$ can be rewritten as:

$E\left(Y_{\mathrm{j}}\right)=\alpha+\beta \pi_{\mathrm{j}}$

and

$\alpha=2 \sigma_{\mathrm{g}}^{2}+2 \sigma_{\mathrm{e}}^{2}$

$\beta=-2 \sigma_{\mathrm{g}}{ }^{2}$

As a supplement to the sib-pair method, an additional method was used to estimate the contribution of locus variation in the LPL gene to systolic blood pressure levels in this data set. At a given locus, in analytic terms, a sib-pair can be considered to be equivalent to a monozygotic twin pair (sharing two alleles identical-by-descent), a dizygotic twin pair (sharing one allele identical-by-descent), or a pair of totally unrelated individuals (sharing zero), respectively. This formulation enables the estimation of heritability from twin data by calculating the contribution of locus variation in the LPL gene to systolic blood pressure levels (39). If we assume that there are no genotypeenvironment interactions, we have a lower estimate of heritability referred to as $H$ (proportion of variance due to genetic factors by the authors [39]):

$H=\left(V_{\mathrm{DZ}}-V_{\mathrm{MZ}}\right) / V_{\mathrm{DZ}}$,

and the standard error:

$S E^{2}(H)=\frac{2\left(V_{\mathrm{MZ}} n_{2}\right)^{2}\left(n_{1}-1\right)\left(n_{1}+n_{2}-4\right)}{\left(V_{\mathrm{DZ}} n_{1}\right)^{2}\left(n_{2}-3\right)^{2}\left(n_{2}-5\right)} ;$

where $V_{\mathrm{MZ}}$ and $V_{\mathrm{DZ}}$ are the variances (between a sibpair) of $n_{1}$ sibpairs sharing two LPL alleles identical-by-descent and $n_{2}$ sib-pairs sharing one LPL allele identical-by-descent, respectively.

\section{Results}

Descriptive statistics and sib-sib correlations for systolic and diastolic blood pressures. Only nondiabetic offspring were included in this study to avoid the potentially confounding effects of NIDDM on blood pressure. Raw systolic and diastolic blood pressure values in these nondiabetic offspring are shown in Fig. 1; normal distributions were observed. All individuals were normotensive, except for three individuals with mildly elevated blood pressures (defined as diastolic blood pressure
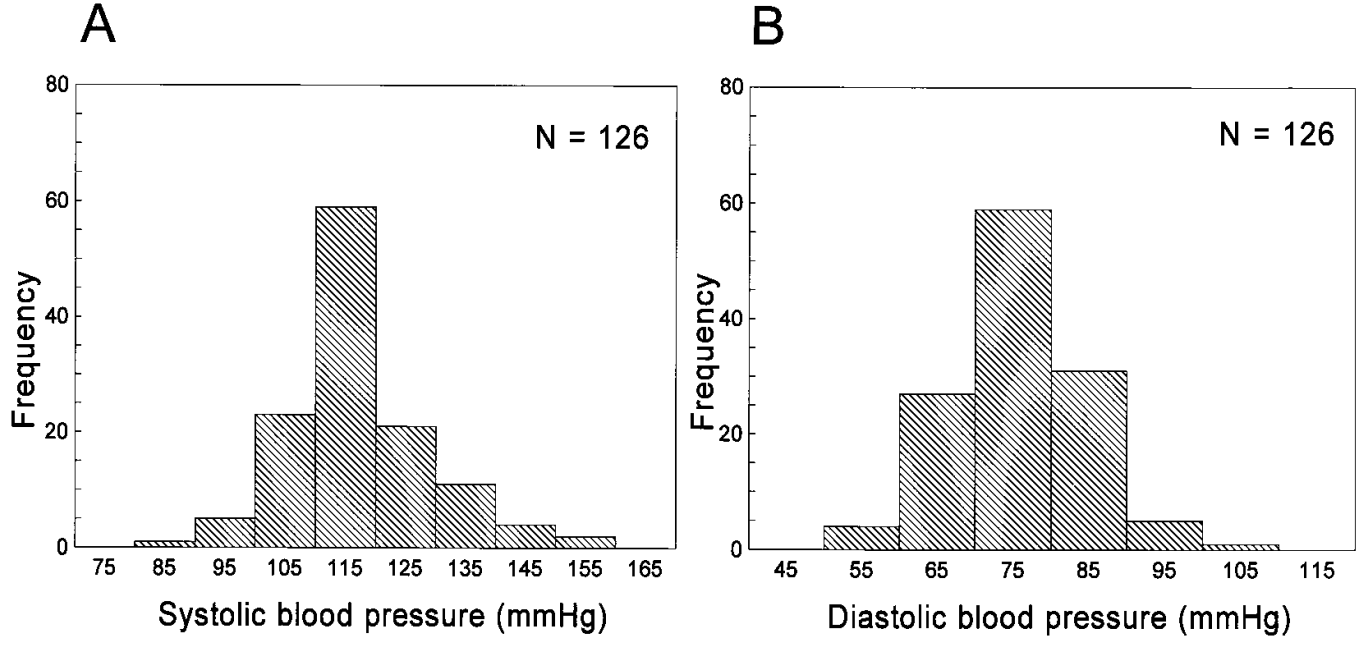

Figure 1. Distribution of blood pressure in 126 nondiabetic offspring. $(A)$ Systolic blood pressure; $(B)$ diastolic blood pressure. 
Table II. Chinese NIDDM Families: Descriptive Statistics in 126 Nondiabetic Offspring

\begin{tabular}{lc}
\hline \multicolumn{1}{c}{ Trait } & Mean \pm SD \\
\hline Age $(\mathrm{yr})$ & $34 \pm 9$ \\
BMI $\left(\mathrm{kg} / \mathrm{m}^{2}\right)$ & $23 \pm 3$ \\
Systolic blood pressure $(\mathrm{mmHg})$ & $115 \pm 13$ \\
Diastolic blood pressure $(\mathrm{mmHg})$ & $74 \pm 9$ \\
Fasting glucose $(\mathrm{mg} / \mathrm{dl})$ & $88 \pm 12$ \\
Fasting insulin $(\mu \mathrm{l} / \mathrm{ml})$ & $15 \pm 7$ \\
\hline
\end{tabular}

$>90 \mathrm{mmHg}$ ). No nondiabetic individuals were taking medication before or at the time of study. Table II lists the mean $( \pm \mathrm{SD})$ age, BMI, systolic blood pressure, diastolic blood pressure, fasting glucose, and fasting insulin of the 126 nondiabetic offspring who were genotyped within these 48 Chinese nuclear families. This is a relatively lean population, with a mean BMI of 23. Sib-sib correlations were 0.18 for systolic blood pressure ( $P<0.02$ in 126 sib-pairs), and 0.21 for diastolic blood pressure $(P<0.005$ in 126 sib-pairs $)$.

Evidence for linkage of systolic blood pressure to the $L P L$ locus on $8 p 22$. We obtained significant evidence for linkage of the LPL gene locus to adjusted systolic blood pressure $(P=$ 0.002 in 125 sib-pairs), but not adjusted diastolic blood pressure $(P=0.73)$. As one way to control for potential type I error, we further genotyped five flanking simple sequence repeat polymorphism (SSRP) markers, consisting of two telomeric markers and three centromeric markers. Four of these five markers demonstrated evidence for linkage with systolic blood pressure, and again none demonstrated any evidence for linkage with diastolic blood pressure (Table III). Two of the markers, D8S282 and neurofilament light polypeptide (NEFL), yielded levels of significance which further support the linkage of LPL locus to systolic blood pressure. Since the levels of significance may be dependent on the informativeness of different markers in individual families, Table III reports the heterozygosity index calculated from this population for each marker. The LODLINK program of S.A.G.E. package was used for calculating two-point linkage distances among LPL and the five other flanking markers. The LOD scores for these two-point linkage analyses ranged from 15 to 21 . Fig. 2 gives the graphic $P$ values and genetic distances among these six linked markers. The genetic distances calculated from this data set for these six linked markers are comparable with those published previously $(20,29)$.

Since one or both parents can be homozygous for a given marker, the identical-by-descent status of a sib-pair in such a case will not be fully determined. This could potentially introduce statistical noise (i.e., loss of power) into our sib-pair linkage analysis. We therefore further analyzed our data, limiting this latter analysis to only those families with fully informative matings for the two most informative markers, LPL and D8S282. Fig. $3 A$ shows these latter linkage results (a negative regression line) of adjusted systolic blood pressure versus the LPL locus on chromosome 8p22 (81 sib-pairs, $P=0.001)$. In contrast, no linkage (a horizontal regression line) was observed for adjusted diastolic blood pressure with the LPL locus (81 sib-pairs, $P=0.97$, Fig. $3 B$ ). We observed similar results for the marker D8S282 which, based on the calculations with this data set, is $3 \mathrm{cM}$ from the LPL locus. Fig. 4, $A$ and $B$, sum-
Table III. Evidence for Linkage of Systolic Blood Pressure to the LPL Gene Region on Chromosome 8 p22

\begin{tabular}{|c|c|c|c|c|c|}
\hline \multirow[b]{2}{*}{ Marker locus } & \multirow{2}{*}{$\begin{array}{l}\text { Heterozygosity } \\
\text { index }\end{array}$} & \multicolumn{2}{|c|}{ Systolic blood pressure } & \multicolumn{2}{|c|}{ Diastolic blood pressure } \\
\hline & & No. of pairs & $P$ value & No. of pairs & $P$ value \\
\hline D8S265 & 0.34 & 120 & 0.14 & 120 & 0.97 \\
\hline D8S261 & 0.70 & 129 & 0.02 & 129 & 0.28 \\
\hline LPL & 0.81 & 125 & 0.002 & 128 & 0.73 \\
\hline D8S282 & 0.81 & 126 & 0.0002 & 129 & 0.75 \\
\hline D8S133 & 0.79 & 118 & 0.01 & 119 & 0.26 \\
\hline NEFL & 0.74 & 123 & 0.001 & 126 & 0.29 \\
\hline
\end{tabular}

marizes these linkage data of the D8S282 locus with adjusted systolic blood pressure $(P=0.0035$ and $n=78)$ and diastolic blood pressure $(P=0.56$ and $n=78)$ in those families with fully informative parental matings.

The contribution of locus variation in the LPL gene to systolic blood pressure levels and intraclass correlations among sib-pairs sharing two, one, and zero LPL alleles identical-bydescent. In this data set, there were 89 sib-pairs in which sharing two, one, and zero LPL alleles identical-by-descent can be unambiguously determined. As expected from the linkage data, we obtained a strong positive correlation, $r=0.37$, among those sib-pairs sharing both LPL alleles identical-bydescent and very interestingly, a negative correlation, $r=$ -0.40 , among those sib-pairs sharing zero LPL allele identicalby-descent. Fig. 5 shows the scatter plot of raw systolic blood pressure for siblings sharing two, one, and zero LPL alleles identical-by-descent. Allelic variation around the LPL gene accounted for $73 \%$ of the total interindividual variation in adjusted systolic blood pressure levels by the sib-pair method. By using the twin derived methodology, an estimate of $52 \%$ with a standard error of $19 \%$ was obtained for the percent contribution of this locus.

Examination of other candidate gene loci for blood pressure. We also tested three other candidate gene loci that have been specifically hypothesized to have a role in the determina-

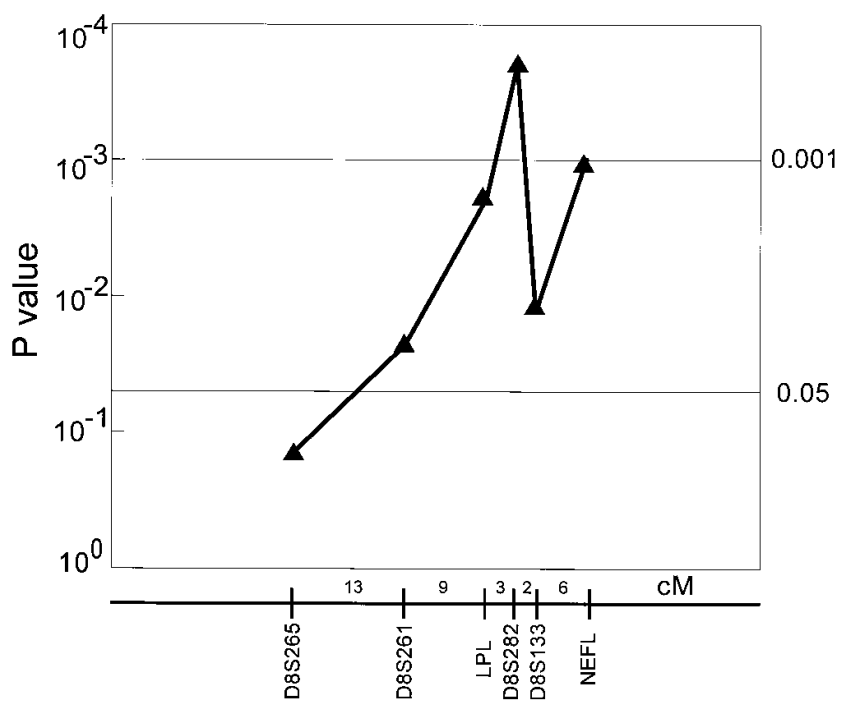

Figure 2. $P$ values from the sib-pair linkage analysis with six markers on chromosome $8 \mathrm{p} 22$. 

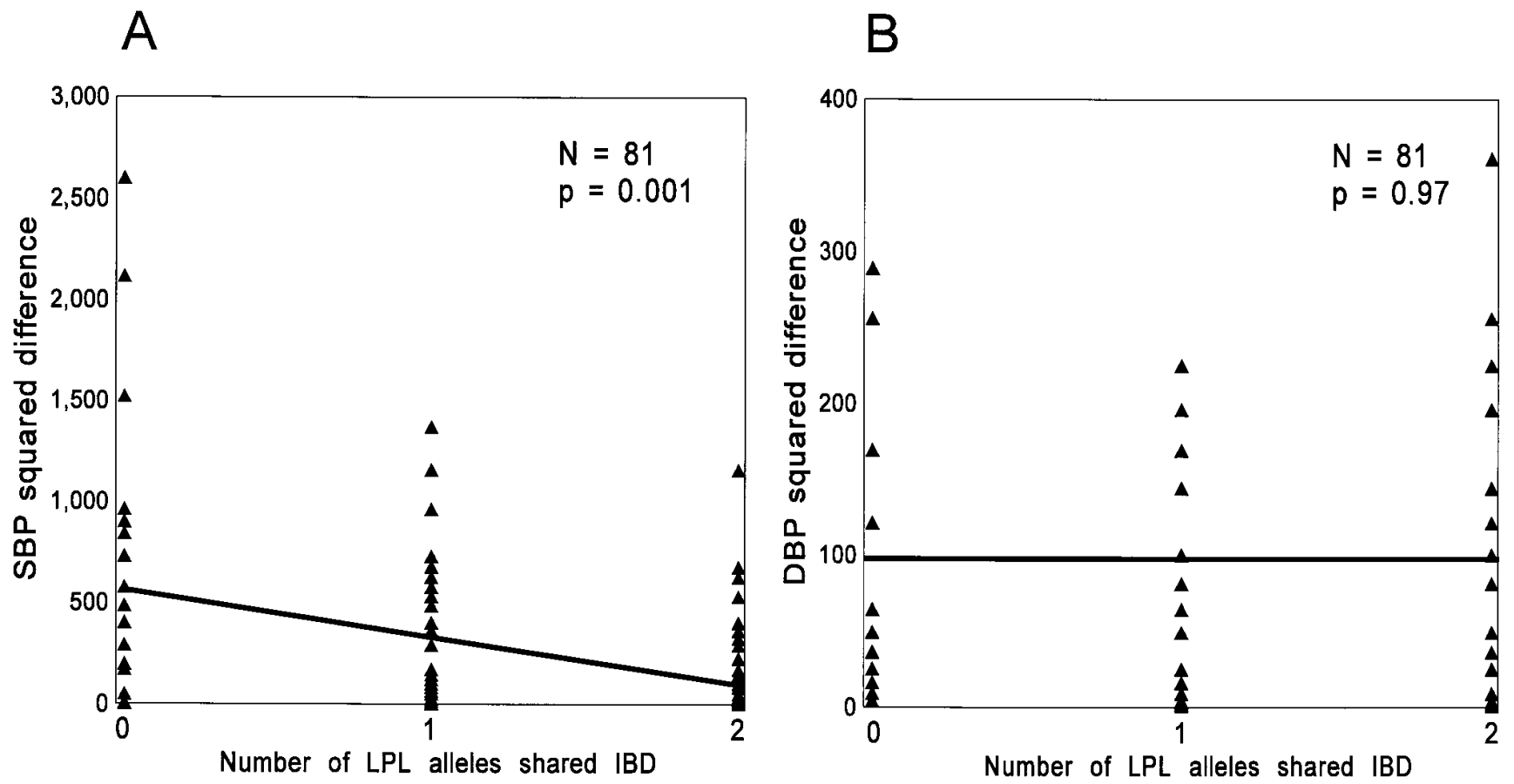

Figure 3. Significant regression of squared trait differences for blood pressure levels versus the number of LPL alleles that a sib-pair shares identical-by-descent $(I B D)$. This figure includes only those sib-pairs whose LPL marker IBD genotypes could be definitely assigned to sharing exactly two, one, and zero alleles at the LPL locus. $(A)$ Systolic blood pressure; $(B)$ diastolic blood pressure.

tion of blood pressure: the ACE gene locus on chromosome $17 q 23$, the angiotensinogen gene locus on chromosome 1q4243 , and the renin gene locus on chromosome 1q32. Three polymorphic markers, one within the ACE gene and two flanking SSRP markers, were genotyped for testing the linkage with
ACE and the results of this analysis are given in Table IV. No evidence for linkage with ACE for either systolic blood pressure or diastolic blood pressure was observed in the offspring (Table IV). For the angiotensinogen gene locus, we typed one RFLP marker and one flanking SSRP marker. Again, no evi-
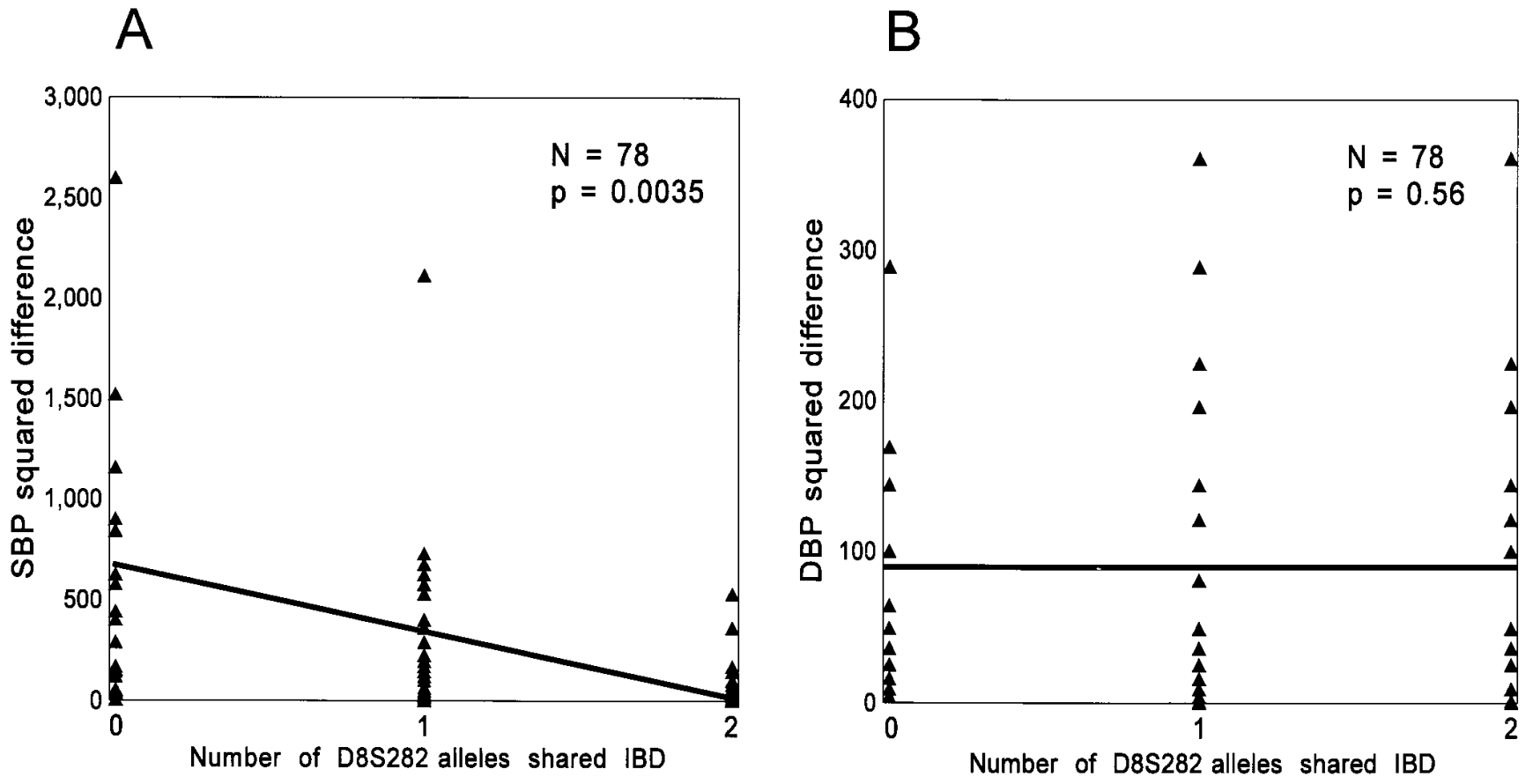

Figure 4. Significant regression of squared trait differences for blood pressure levels versus the number of D8S282 alleles that a sib-pair shares identical-by-descent $(I B D)$. This figure includes only those sib-pairs whose D8S282 marker IBD genotypes could be definitely assigned to sharing exactly two, one, and zero alleles at the D8S282 locus, which is $3 \mathrm{cM}$ from the LPL locus. $(A)$ Systolic blood pressure; $(B)$ diastolic blood pressure. 


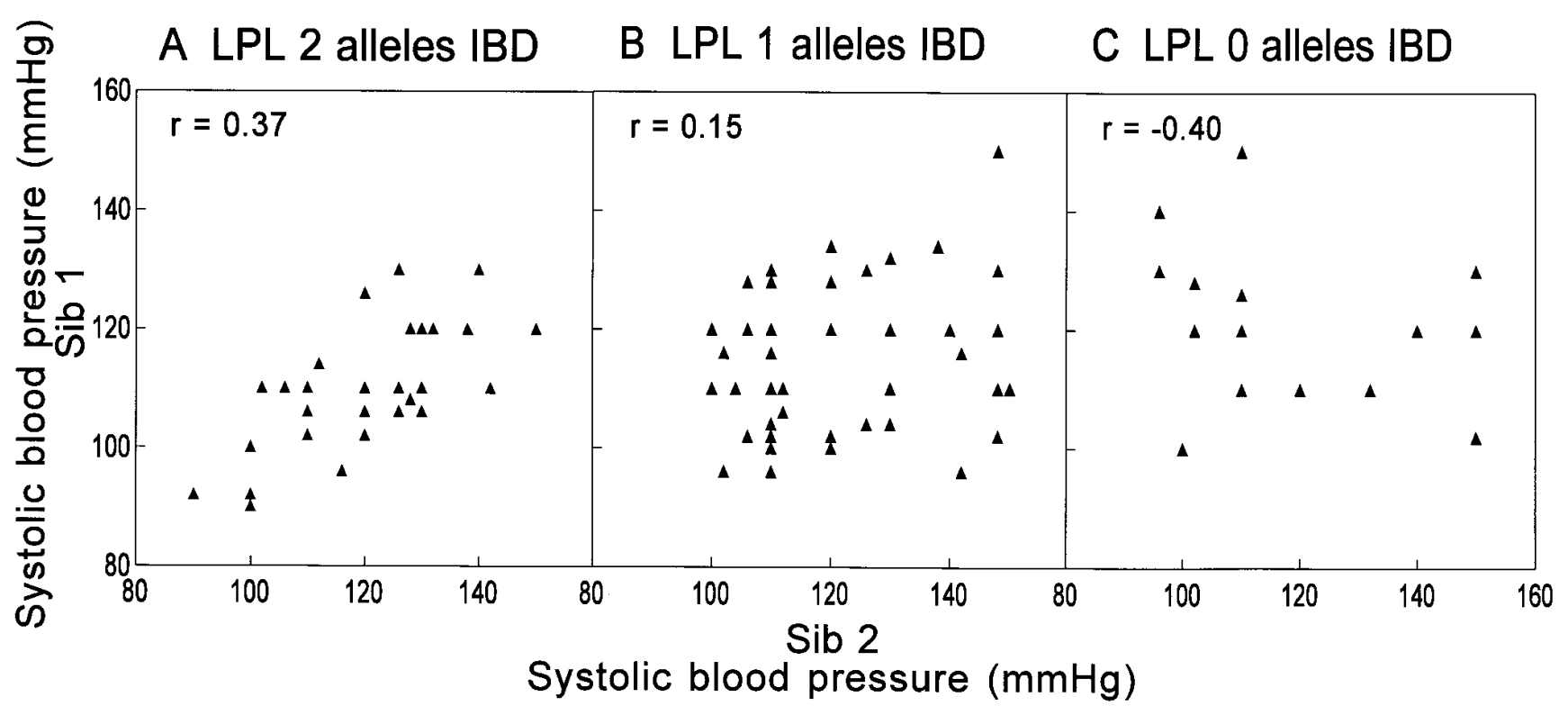

Figure 5. Scatter plot of systolic blood pressure levels for sibling pairs sharing both LPL alleles $(A)$, one LPL allele $(B)$, or zero LPL alleles $(C)$ identical-by-descent $(I B D)$.

dence for linkage of the angiotensinogen locus with either systolic blood pressure or diastolic blood pressure was observed (Table IV). The renin gene locus was examined for linkage by typing an SSRP marker within the renin gene. Again, we did not observe evidence for linkage of this locus to a locus controlling either systolic blood pressure or diastolic blood pressure variation in this population (Table IV).

Other candidate gene loci tested in this population. We also tested a number of other candidate gene loci in this population at high risk for NIDDM (Table I). None of these loci, related to either glucose/insulin or lipid metabolism, showed evidence for linkage $(P<0.05)$ with either systolic blood pressure or diastolic blood pressure.

\section{Discussion}

In an effort to identify genetic factors contributing to the association between NIDDM and blood pressure, we have examined the gene markers residing within or near various candidate genes in families ascertained through probands with NIDDM. Quantitative sib-pair linkage analysis of the unaffected offspring of these families revealed evidence of linkage of systolic blood pressure to the LPL gene locus on chromosome 8 . Linkage was further supported with several closely linked informative markers. Allelic variation around the LPL gene locus accounted for an estimate of $52-73 \%$ of the total interindividual variation in systolic blood pressure levels in this data set, though this estimate has a large confidence interval. In contrast, no evidence of linkage with blood pressures was observed with markers at the ACE gene locus on chromosome $17 q 23$, the angiotensinogen gene locus on chromosome 1q4243 , and the renin gene locus on chromosome 1q32.

The pathophysiologic basis of the linkage of the LPL gene with systolic blood pressure is not apparent at this time. Indeed, it could be argued that the association between blood pressure and the gene that codes for an extracellular enzyme that hydrolyzes triglycerides in plasma is unlikely to have any physiological meaning. On the other hand, there are recent ob- servations that suggest that there may well be a functional relationship between mutations in the LPL gene and blood pressure. For example, it has been shown in one pedigree that heterozygotes with a specific missense mutation at codon 188 of the LPL gene were hypertensive when they were both over $40 \mathrm{yr}$ old and hypertriglyceridemic (40-42). Moreover, a recent unpublished study of a number of families with different LPL mutations showed that individuals who were heterozygous for different LPL mutations had higher systolic blood pressure than their homozygous normal siblings (Sprecher, D., personal communication). Consistent with a possible role of the LPL gene in the regulation of blood pressure was the finding that the gene is located near the peak $P$ value for the various markers at the chromosome 8 locus linked with systolic blood pressure (Fig. 2). The fact that the LPL gene does not occur precisely at the peak could be due to differences in informativeness of the markers in certain families which contribute differentially to the sib-pair linkage analysis, depending on the extent of variation of blood pressure in individual families. Therefore,

Table IV. Lack of Linkage of Blood Pressure to Vascular Candidate Gene Loci

\begin{tabular}{|c|c|c|c|c|}
\hline \multirow[b]{2}{*}{ Marker locus } & \multicolumn{2}{|c|}{ Systolic blood pressure } & \multicolumn{2}{|c|}{ Diastolic blood pressure } \\
\hline & No. of pairs & $P$ value & No. of pairs & $P$ value \\
\hline \multicolumn{5}{|c|}{ ACE locus on chromosome $17 q 23$} \\
\hline $\mathrm{ACE} \mathrm{I} / \mathrm{D}$ & 139 & 0.50 & 139 & 0.73 \\
\hline Growth hormone & 137 & 0.26 & 137 & 0.49 \\
\hline D17S787 & 119 & 0.23 & 119 & 0.85 \\
\hline \multicolumn{5}{|c|}{ Angiotensinogen locus on chromosome $1 \mathrm{q} 42-43$} \\
\hline AGTN RFLP & 139 & 0.11 & 138 & 0.87 \\
\hline AGTN SSRP & 119 & 0.98 & 119 & 0.77 \\
\hline \multicolumn{5}{|c|}{ Renin gene locus on chromosome 1q32 } \\
\hline Renin SSRP & 104 & 0.11 & 104 & 0.38 \\
\hline
\end{tabular}


uninformativeness of the LPL markers in one or more families with informative mating regarding systolic blood pressure phenotypes, e.g., one sib low and one sib high, could explain the difference in $P$ values in the sib-pair linkage analysis from one marker locus to the next. In the future, with the continued development of nonparametric linkage methodology, approaches such as interval mapping of QTL proposed by Fulker and Cardon (43) could be applied to further narrow this interval. On the other hand, it is also possible that a gene other than LPL in this region is responsible for association with systolic blood pressure. For example, Hoehe et al. (44) reported that alpha-1C adrenergic receptor gene is closely linked $(\theta=0.03)$ to the NEFL gene, which itself located about $11 \mathrm{cM}$ centromeric to the LPL gene. Obviously, the ultimate significance of the linkage between the LPL gene and systolic blood pressure observed in this study will depend upon further experiments aimed at evaluating that issue directly.

The quantitative contribution of variation at the LPL locus to systolic blood pressure levels was estimated by two different methods, i.e., sib-pair linkage and twin derived methodologies. Two estimates of the contribution of variation or heritability at the LPL locus to systolic blood pressure levels, 73 and 52\%, respectively, were obtained with a standard error that would include the range $14-18 \%$ to $90 \%$ to $94 \%$ for the latter one. Heritability estimates for systolic blood pressure have ranged from 13 to $82 \%$ in various studies, with average levels of $\sim 50 \%$ (45). One classic twin study on MZ twins and their families yielded an estimate of 0.47 for the heritability of systolic blood pressure (46).

The renin-angiotensin system plays an important role in the functioning of cardiovascular system and the regulation of blood pressure (47). Neither the renin or the ACE genes have shown evidence for linkage with blood pressure in humans, although the renin gene variations influence blood pressure in rodent models (48). The angiotensinogen gene, on the other hand, exhibits linkage to essential hypertension in certain human populations $(35,49)$ and in rodent models $(50)$. In the population studied herein, no evidence of significant linkage was observed between renin, angiotensinogen, or the ACE gene loci and either measure of blood pressure. The failure to observe linkage with the angiotensinogen gene locus in our study may be due to population differences or the fact that the subjects in our population did not, in general, exhibit elevated blood pressure and were not primarily ascertained from families with hypertension. Both of these explanations imply that variation in human blood pressure can occur by different genetic mechanisms as a function of either ethnicity or disease process. In addition to these candidate gene approaches, tentative evidence has been reported for a locus contributing to diastolic blood pressure on the short arm of chromosome 1, using classical protein polymorphic markers (51).

Some discussion regarding the statistical methods used in this study is warranted. The underlying basis for quantitative sib-pair linkage method is to compare the quantitative variation in a trait between siblings as a function of the marker alleles they share identical-by-descent at the test locus $(12,13,52)$. When compared with the LOD score method, this approach has a major advantage of not requiring specification of a genetic model. This is particularly important for studying a complex trait such as blood pressure. The linkage of a gene controlling systolic blood pressure to the LPL gene locus on chromosome 8p22 should be considered preliminary, as should all first linkage reports, especially for complex phenotypes. However, we feel that the systolic blood pressure linkage result has a favorable likelihood of confirmation, given: $(a)$ the robustness of the analysis to various restrictions on informativeness of parental marker genotypes; $(b)$ four linked markers in a $20 \mathrm{cM}$ region flanking the LPL locus all providing evidence for linkage of systolic blood pressure; $(c)$ published data showing that mutations in the LPL gene are associated with higher blood pressure; and $(d)$ alternatively, that there is another prime candidate gene in this region, the alpha- $1 \mathrm{C}$ adrenergic receptor gene, which is physiologically related to regulation of blood pressure in human beings.

In conclusion, quantitative sib-pair analysis in the nondiabetic members of Chinese type II diabetes families living in Taiwan has provided evidence for genetic linkage between the D8S261, LPL, D8S282, and NEFL loci, all located on chromosome $8 \mathrm{p} 22$, and a putative gene determining systolic blood pressure. Allelic variation at the LPL gene locus accounted for an estimated $52-73 \%$ of the total interindividual variation in systolic blood pressure levels in this data set. Because blood pressure is a major risk factor for coronary heart disease, it will be important to determine whether essential hypertension or hypertension in diabetic patients is linked to this identified locus.

\section{Acknowledgments}

This work was supported by National Institutes of Health grants HL42481 (A.J. Lusis, C.H. Warden, X. Bu, and J.I. Rotter) and HL08506 (G.M. Reaven and Y.-D.I. Chen). D.-A. Wu, D.D.C. Shen, C.-Y. Jeng, W.H.H. Sheu, and M.M.T. Fuh were supported by grant DOH 83,84-HR-302 (National Health Research Institute, Taiwan). J.I. Rotter and X. Bu were also supported by a grant from the Stuart Foundations, GCRC grant RR0042525S3, and the Cedars-Sinai Board of Governors' Chair in Medical Genetics. The results of sibpair analysis and two-point linkage analysis were obtained by using the program package S.A.G.E., which is supported by U.S. Public Health Service resource grant 1 P41 RR03655 from the Division of Research Resources.

\section{References}

1. Rich, S. 1990. Mapping genes in diabetes: genetic epidemiological perspective. Diabetes. 39:1315-1319.

2. Warram, J.H., B. C. Martin, A.S. Krolewski, J.S. Soeldner, and C.R Kahn. 1990. Slow glucose removal rate and hyperinsulinemia precede the development of type II diabetes in the offspring of diabetic parents. Ann. Intern. Med. 113:909-915.

3. Rotter, J.I., C.M. Vadheim, and D.L. Rimoin. 1992. Diabetes mellitus. In The Genetic Basis of Common Diseases. R.A. King, J.I. Rotter, and A.G. Motulsky, editors. Oxford University Press, New York. 413-481.

4. Reaven, G.M. 1988. Role of insulin resistance in human disease. Diabetes. 37:1595-1607.

5. Leahy, J.L., and A.E. Boyd III. 1993. Diabetes genes in non-insulindependent diabetes mellitus. N. Engl. J. Med. 328:56-57.

6. Królewski, A.S., A. Czyzyk, J. Kopczynski, and S. Rywik. 1981. Prevalence of diabetes mellitus, coronary heart disease and hypertension in the families of insulin dependent and insulin independent diabetes. Diabetologia. 21: $520-524$.

7. Eriksson, J., A. Franssila-Kallunki, A. Ekstrand, C. Saloranta, E. Widen, C. Schalin, and L. Groop. 1989. Early metabolic defects in persons at increased risk for non-insulin-dependent diabetes mellitus. N. Engl. J. Med. 321:337-343.

8. Laws, A., M.L. Stefanick, and G.M. Reaven. 1989. Insulin resistance and hypertriglyceridemia in nondiabetic relatives of patients with noninsulindependent diabetes mellitus. J. Clin. Endocrinol. \& Metab. 69:343-347.

9. Ho, L.T., Z.Y. Chang, J.T. Wang, S.H.Li, Y.F. Liu, Y.D.I. Chen, and G.M. Reaven. 1990. Insulin insensitivity in offspring of parents with type 2 diabetes mellitus. Diabetic. Med. 7:31-34.

10. Klein, R., B.E.K. Klein, S.E. Moss, and D.L. DeMets. 1986. Blood pressure and hypertension in diabetes. Am. J. Epidemiol. 122:75-89.

11. Kannel, W.B., A. Gordon, and M.J. Schwartz. 1971. Systolic versus dia- 
stolic blood pressure and risk of coronary heart disease. Am. J. Cardiol. 27:335346 .

12. Haseman, J.K., and R.C. Elston. 1972. The investigation of linkage between a quantitative trait and a marker locus. Behav. Genet. 2:3-19.

13. Amos, C.I., R.C. Elston, A.F. Wilson, and J.E. Bailey-Wilson. 1989. A more powerful robust sib-pair test of linkage for quantitative traits. Genet. Epidemiol. 6:435-449.

14. S.A.G.E. Statistical analysis for genetic epidemiology, release 2.1. 1992. Computer program package available from the Department of Biometry and Genetics, Louisiana State University Medical Center, New Orleans.

15. National Diabetes Data Group International Workgroup. 1979. Classification of diabetes mellitus and other categories of glucose intolerance. Diabetes. 28:1039-1057.

16. Kadish, A.H., R.L. Litle, and J.C. Sternberg. 1968. A new and rapid method for determination of glucose by measurement of rate of oxygen consumption. Clin. Chem. 14:116-131.

17. Hales, C.N., and P.J. Randle. 1963. Immunoassay of insulin with insulinantibody precipitate. Biochem. J. 88:137-146.

18. Tanizawa, Y., K.C. Chiu, M. A. Province, R. Morgan, D.R. Owens, A. Ress, and M.A. Permutt. 1993. Two microsatellite repeat polymorphisms flanking opposite ends of the human glucokinase gene: use in haplotype analysis of Welsh Caucasians with type 2 (non-insulin-dependent) diabetes mellitus. Diabetologia. 36:409-413.

19. Economou, E.P., A.W. Bergen, A.C. Warren, and S.E. Antonarakis. 1990. The polydeoxyadenylate tract of Alu repetitive elements is polymorphic in the human genome. Proc. Natl. Acad. Sci. USA. 87:2951-2954.

20. Gyapay, G., J. Morissette, A. Vignal, C. Dib, C. Fizames, P. Millasseau, S. Marc, G. Bernardi, M. Lathrop, and J. Weissenbach. 1994. The 1993-1994 Genethon human genetics linkage map. Nat. Genet. 7:246-339.

21. Patel, M.S., B.S. Mankoo, and P.M. Brickell. 1992. A polymorphic microsatellite repeat is located close to the promoter region of the c-fgr protooncogene (FGR) at chromosome 1p36.2-p36.1. Hum. Mol. Genet. 1:65.

22. Stoffel, M., R. Espinosa, S. R. Keller, G.E. Lienhard, M.M. Le Beau, and G.I. Bell. 1993. Human insulin receptor substrate-1 (IRS1): chromosomal localization to 2q35-q36.1 and identification of a simple tandem repeat DNA polymorphism. Diabetologia. 36:335-337.

23. Glaser, B., K.C. Chiu, R. Anker, A. Nestorowicz, H. Landau, H. BenBasset, Z. Shlomai, N. Kaiser, P. S. Thronton, C. A. Stanley, et al. 1994. Familial hyperinsulinism maps to chromosome $11 \mathrm{p} 14-15.1 \mathrm{cM}$ centromeric to the insulin gene. Nat. Genet. 7:185-188.

24. Bu, X., C. H. Warden, Y. R. Xia, C. DeMeester, D.L. Puppione, S. Teruya, B. Lokensgard, S. Daneshmand, J. Brown, R.J. Gray, J.I. Rotter, and A.J. Lusis. 1994. Linkage analysis of the genetic determinants of high density lipoprotein concentrations and composition: evidence for involvement of the apolipoprotein A-II and cholesterol ester transfer protein loci. Hum. Genet. 93:636648.

25. Zuliani, G., and H.H. Hobbs. 1990. Tetranucleotide repeat polymorphism in the apolipoprotein C-III gene. Nucl. Acids Res. 18:4299.

26. Weber, J.L., and P.E. May. 1989. Abundant class of human DNA polymorphisms which can be typed using the polymerase chain reaction. Am. J. Hum. Genet. 44:388-396.

27. Hudson, T.J., M. Engelstein, M.K. Lee, E.C. Ho, M.J. Rubenfield, C.P. Adams, D.E. Houseman, and N.C. Dracopoli. 1992. Isolation and chromosomal assignment of 100 highly informative human simple sequence repeat polymorphisms. Genomics. 13:622-629.

28. Wood, S., M. Schertzer, M. Hayden, and Y. Ma. 1993. Support for founder effect for two lipoprotein lipase (LPL) gene mutations in French Canadians by analysis of GT microsatellites flanking the LPL gene. Hum. Genet. 91: 312-316.

29. Matise, T.C., M. Perlin, and A. Chakravarti. 1994. Automated construction of genetic linkage maps using an expert system (MultiMap): a human genome linkage map. Nat. Genet. 6:384-390.

30. Rogaev, E., E. Rogaeva, W.J. Lukiw, G. Vaula, Y. Liang, R. Hancock, D.C. McLachlan, and P.H. St. George-Hyslop. 1992. An informative microsatellite repeat polymorphism in the human neurofilament light polypeptide (NEFL) gene. Hum. Mol. Genet. 1:781.

31. Wood, S., H.K. Mitchell, and M. Schertzer. 1991. Isolation and analysis of dinucleotide repeat polymorphisms from a flow-sorted chromosome 8 li- brary. Cytogenet. Cell Genet. 58:1932.

32. Cambien, F., O. Poiner, L. Lacerf, A. Evans, J.P. Cambou, D. Arveiler, G. Luc, J.M. Bard, L. Bara, S. Ricard, et al. 1992. Deletion polymorphism in the gene for angiotensin-converting enzyme is a potent risk factor for myocardial infarction. Nature (Lond.). 359:641-644.

33. Jeunemaitre, X., R.P. Lifton, S.C. Hunt, R.R. Williams, and J.-M. Lalouel. 1992. Absence of linkage between the angiotensin converting enzyme locus and human essential hypertension. Nat. Genet. 1:72-75.

34. Edwards, A., H.A. Hammond, L. Jin, C.T. Caskey, and R. Chakraborty. 1992. Genetic variation at five trimeric and tetrameric tandem repeat loci in four human population groups. Genomics. 12:241-253.

35. Jeunemaitre, X., F. Soubrier, Y.V. Kotelevtser, R.P. Lifton, C.S. Williams, A. Charru, S.C. Hunt, P.N. Hopkins, R.R. Williams, J.M. Lalouel, and P. Corvol. 1992. Molecular basis of human hypertension: role of angiotensinogen. Cell. 71:169-180.

36. Kotelevtsev, Y.V., E. Clauser, P. Corvol, and F. Soubrier. 1991. Dinucleotide repeat polymorphism in the human angiotensinogen gene. Nucl. Acids Res. 19:6978.

37. Dixon, W.J. 1992. BMDP Statistical Software Manual. University of California Press, Berkeley.

38. Boerwinkle, E., C.C. Leffert, J. Lin, C. Lackner, G. Chiesa, and H. Hobbs. 1992. Apolipoprotein(a) gene accounts for greater than $90 \%$ of the variation in plasma lipoprotein(a) concentrations. J. Clin. Invest. 90:52-60.

39. Cavalli-Sforza, L.L., and W.F. Bodmer. 1971. The Genetics of Human Populations. W.H. Freeman and Company, San Francisco. 573-597.

40. Williams, R.R., S.C. Hunt, S.J. Hasstedt, P.N. Hopkins, L.L. Wu, T.D. Berry, B. M. Stults, G. K. Barlow, M. Catherine-Schmacher, R.P. Lifton, and J.M. Lalouel. 1990. Multigenic human hypertension: evidence for subtypes and hope for haplotypes. J. Hyperten. 8(Suppl. 7):S39-S46.

41. Williams, R.R., S.C. Hunt, P.N. Hopkins, L.L. Wu, S. J. Hasstedt, T.D Berry, B.M. Barlow, M. C. Schumacher, E.H. Ludwif, S.C. Elbein, et al. 1993. Genetic basis of familial dyslipidemia and hypertension: 15-year results from Utah. Am. J. Hyperten. 6:319S-327S.

42. Wilson, D.E., M. Emi, P.H. Iverius, A. Hata, L.L. Wu, E. Hillas, R.R. Williams, and J. M. Lalouel. 1990. Phenotypic expression of heterozygous lipoprotein lipase deficiency in the extended pedigree of a proband homozygous for a missense mutation. J. Clin. Invest. 86:735-750.

43. Fulker, D.W., and J.R. Cardon. 1994. A sib-pair approach to interval mapping of quantitative trait loci. Am. J. Hum. Genet. 54:1092-1103.

44. Hoehe, M.R., W.H.Berrettini, D.A. Schwinn, and W.T. Hsieh. 1992. A two-allele Pstl RFLP for the alpha-1C adrenergic receptor gene (ADRA1C). Hum. Mol. Genet. 1:349.

45. Hopkins, P.N., and R.R. Williams. 1989. Human genetics and coronary heart disease: a public health perspective. Ann. Rev. Nutr. 9:303-345.

46. Ewell, L.W., W.E. Nance, L.A. Corey, J.A. Boughman, and P.M. Winter. 1978. Blood pressure studies on monozygotic twins and their families. In Twin Research: Clinical Studies. W.E. Nance, editor. Alan R. Liss, Inc., New York. 29-38.

47. MacGregor, G.A., N.D. Markandu, J.E. Roulston, J.C. Jones, and J.J. Morton. 1981. Maintenance of blood pressure by the renin-angiotensin system in normal man. Nature (Lond.). 291:329-331.

48. Kurtz, T.W., I. Simonet, K.M. Potear, S. Wolfe, L. Chan, and P.I. Hjelle. 1990. Cosegregation of the renin allele of the spontaneously hypertensive rat with an increase in blood pressure. J. Clin. Invest. 85:1328-1332.

49. Caulfield, M., P. Lavender, M. Farrall, P. Munroe, M. Lawson, P. Turner, and A.J.L. Clark. 1994. Linkage of the angiotensinogen gene to essential hypertension. N. Engl. J. Med. 330:1629-1633.

50. Kimura, S., J.J. Mullins, B. Bunnenann, R. Metzger, U. Hilgenfeldt, F. Zimmermann, H. Jacob, K. Fuxe, D. Ganter, and M. Kahing. 1992. High blood pressure in transgenic mice carrying the rat angiotensinogen gene. $E M B O$ (Eur. Mol. Biol. Organ.) J. 11:821-827.

51. Wilson, A.F., R.C. Elston, L.D. Tran, and R.M. Siervogel. 1991. Use of the robust sib-pair method to screen for single-locus, multiple-locus, and pleiotropic effects: application to traits related to hypertension. Am. J. Hum. Genet 48:862-872.

52. Ott, J. 1991. Methods of linkage analysis: nonparametric approaches. In Analysis of Human Genetic Linkage. Revised edition. Johns Hopkins University Press, Baltimore. 77-80. 